\title{
The Relation Between Self-Esteem Development and Learning Breaststroke Swimming Performance
}

\author{
Dr. Khitam Mousa Ay \\ Department of supervision and teaching, \\ Faculty of physical education, The University of Jordan
}

doi: 10.19044/esj.2016.v12n20p164 URL:http://dx.doi.org/10.19044/esj.2016.v12n20p164

\begin{abstract}
This study investigates the relation between self-esteem development and learning to perform the breaststroke swimming skill. Twenty four female students from physical education faculty at the university of Jordan (19 \pm 0.5 ) years of age, who were assigned in swimming course (2) in the first semester 2014/2015. After completing the self-esteem Questionnaire (Robson Self-Esteem Questionnaire, 1989) the subjects were randomly divided into two groups: experimental group $(n=12)$ received physical practice of the breaststroke swimming skill performance, and dialogues for self-esteem development, and control group $(n=12)$ received only physical practice of the breaststroke swimming skill performance.

Two measurements were taken; both groups were measured at the beginning (pre-test), in order to establish that all students started at the same level of performance and global self-esteem level, after the pre-test of the breaststroke skills performance, all subjects filled out the self-esteem questionnaire. After the completion of the intervention the final measurements were taken (post-test), to note the impact of the intervention on the student's performance in breaststroke swimming skills and selfesteem improvement.

Statistical analysis included t-Test for mean at pre and post test for the two groups and t-Test for mean at post test in the two groups. The results showed significant differences ( $\mathrm{p}<0.05$ ) in post test between the two groups in favor of the experimental group. In conclusions learning new swimming skills performance engaged to dialogues for self-esteem development enhanced learning and improved skills performance of the breaststroke swimming.
\end{abstract}

Keywords: Breaststroke Swimming, Self-Esteem Questionnaire, Performance, Learning, Dialogues 


\section{Introduction}

Since the dawn of mankind, there were many reasons why humans seek to learn swimming, which is understood as locomotion, balance, and ability to perform breathing cycles during propulsion in the water (Santos et al., 2008).

Swimming is a special sport based on water, as it requires a particular environment to perform compared with other land-based sports; it presents higher requirements to achieve high quality teaching (Ting, 2015). These requirements are derived primarily from the fact that the work in water, the medium opposing a specific resistance of the body which is at the same time in a less normal position. The main request is addressed to feelings of balance and body orientation under water immersion. In the activity of learning how to swim, there are involved some difficulties of accommodating to the water, specific breathing skills, coordination of arms movement with those of legs and breathing; it is known that water immersion adversely affects kinesthetic sense and balance, and so, diving representations, a particular aspect is jumping from the tower or the trampoline where, as in gymnastics, it is appreciated the athlete's skill in leading the body to complicated and difficult exercises in terms of coordination(Dalgas-Pelish, 2006). Specific swimming styles which are part of the syllabus of swimming courses in physical education faculties, and which the students have to pass its physical subjective skills performance exams. These, however, involve the formation of complex motor skills, motor skills involve internal processes that occur in the central nervous system of the performer (Epuran et al., 2001).Usually, swimming learning exceeds motor behavior goals, and is supported by issues related to water safety, leisure, recreation, and physical and sports training (Machado, 2006), while one of the difficulties faced by swimming teachers is to establish motivational strategies for their students, considering that the movements used in the learning process are usually repetitive (Canossa et al., 2007).

Research in Sport Psychology considers motivation as a behavior directed toward a goal or the internal and emotional awakening interest in something being willing to reach it (Machado,2006), and its importance is associated with adherence to physical practice, income, physical conditioning, fun, learning and living with friends, and success experience (Moreno et al., 2006).

Studies on learning and motor control have not contributed much to the search for solutions related to students' motivational problems during the swimming learning process (Canossa et al., 2007). This aspect calls for a reorientation of the studies, focus toward variables that effect motor learning in swimming, which, ultimately, are the factors addressed by professionals dealing with motor skills learning in a real situation of practice. Perceived 
ability, and perceived competence have been used to describe one's perceived capability to accomplish a certain level of skills performance in this area (Bandura, 1977). In addition, as Bandura (1978) notes, self-efficacy is not concerned with the skills an individual has but with the judgments of what an individual can do with the skills he or she possesses. Bandura prefers to use the term "self-efficacy" to specify the level of perceived competence and the strength of that belief "perceived competence", and "perceived ability" are terms that have been limited in use to the achievement and mastery motivation literature, and indicate the sense that one has the ability to master a task resulting from cumulative interactions with the environment (Harter, 1978). In the specific area of sport and movement, Interdependence between mind and body was not only recognized but also highlighted as being of central importance for achieving sport skills performance and personality development in sports psychology, it's about improving attitude and mental game skills to help the learner perform his/her best by identifying limiting beliefs and embracing a healthier philosophy about his/ her sport (Hanton \& Jones, 1999). Any type of learning process, the organization of practice (Pellegrini, 2000), and the use of psychological training are essential factors for acquiring new motor skills performance, by changing the inner state and emotional awaking interest in something which keeps the learners moving forward, causing them to like more the task, try more, and be more willing to practice it for a longer period (Magill, 2007).

Psychological skills training programs are an opportunity to nurture positively young athletes personal development in competitive sport, and to facilitate their growth in other areas of their life by generalizing the use of psychological skills, there has been an increased international awareness of the usefulness of psychological skills training for young people (Tremayne \& Tremayne , 2004). For example in the Swedish and Australian school system, Tremayne and Tremayne ( 2004) have identified successful implementations of the teaching of goal setting, imagery, relaxation and stress management in order to improve physical fitness, self-confidence and self-esteem.

Self-esteem is one of the most important psychological concepts that affect motor learning, it's the degree worth and competence that we attribute to ourselves; it's a feeling of having respect for yourself and your abilities which gives you a motivational push to learn something new. Self-esteem is an important aspect of the academic, social and emotional development of students (Coopersmith, 1981). There are many different definitions given to self-esteem, for some, self-esteem is the conscious appreciation of our own worth and importance, the reputation we have with ourselves. For others, the need to be responsible for ourselves and to act responsibly is paramount. Some believe self-esteem judgments reflect evaluations based on 
"differentiating characteristics." That means the judgments derive from social comparisons, which provide the basis for a person's esteem. Others think self-esteem is an entitlement of personhood and should be equated with self-respect (Kahne, 1996). Lishner (1997) states that self-esteem consists of the evaluative judgments children make about their characteristics and qualities, including their attitude about themselves and their sense of worthiness. According to Lishner (1997) a well known early researcher, selfesteem reflects the extent to which people believe themselves to be capable, significant, successful, and worthy.

Healthy self-esteem has been associated with happiness, success, and high achievement, whereas low self-esteem has been associated with depression, anxiety, and underachievement (Addeo 1994). What is uncertain, however, is whether higher self-esteem results due to success, or success results in higher self-esteem. Self-esteem is the regard you hold for yourself (self-concept), When students feel positive self-esteem, they are more readily able to turn sporting potential into superior performance, conversely, when they feel negative self-esteem, the slightest setback performance or smallest hurdle can have an inordinate effect on their performance (Cohn, 2006). Experts agree that high self-esteem is one of the most important developments in childhood; child-development experts generally categorize self-esteem within the emotional/social domain of development (Lishner, 1997), this domain includes feelings, beliefs, temperament, relationships with others, self-concept, gender identity, and moral development. Young people's levels of social, emotional, physical, and cognitive development interact with their environmental experiences and messages to shape selfesteem (Machado, 2006).

Lishner (1997, p67) summarized the characteristics of high selfesteem and low self-esteem, which are listed in the following table:

\begin{tabular}{|c|c|}
\hline High self-esteem & Low self-esteem \\
\hline - Display initiative, independence, curiosity, & - Do not display initiative, independence, \\
confidence. & curiosity, confidence. \\
- Show pride in their work & - Do not show pride in their work. \\
- Trust their ideas. & - Do not trust their ideas. \\
- Set goals independently. & - Do not explore. \\
- Explore and ask questions. & - Lack confidence to initiate or approach \\
- Initiate activities with confidence. & activities. \\
- Adapt to change or stress. & - Have difficulty reacting to change or \\
- Handle teasing and criticism. & stress. \\
- Tolerate frustration. & - Showing immature behavior when facing \\
- Are comfortable with transitions. & stress. \\
- Can adjust to change. & - Hang back or withdraw, sit apart. \\
- Describe self in positive terms. & - Give up easily when frustrated. \\
- Have a cheerful mood. & - React inappropriately to accidents \\
- Do not display initiative. & - Describe self in negative terms. \\
& - Display a depressed mood. \\
\hline
\end{tabular}


We may enhance our self- esteem through sport by having a positive image of our bodies, and the physical skills and abilities that we develop. We feel positive self worth through the recognition that we receive from family and friends and the social relationships that develop as a result of our involvement in sport and physical activity (Magill, 2007). Yet, we may be vulnerable to low self-esteem in sport and physical activity if we perceive our body to be inadequate, unfit or inappropriate for our selected activity, we may feel that our self-worth is judged on our losses and wins versus our abilities and intentions (Lishner, 1997). The intensive participation in sport may lead to social isolation and lack of family support. All of these negative emotions need to be refocused in order to build positive self-esteem. Coaches, physical education teachers and active living leaders can positively influence self-esteem and provide girls and women with ongoing incentive to participate and personally succeed in physical activity endeavors (Coopersmith, 1981).

Students with high self-esteem often show increased school performance, improved health, and more productive behaviors; on the other hand, low self-esteem in children has been linked to poor academic achievement, depression, smoking, and other deleterious social behaviors. Schools and educators are in a unique position to be able to teach children strategies to raise self-esteem, provide guidance and follow up activities, and monitor the impact of self-esteem enhancement education over time. (Zevin \& McPherson1989). The positive findings of the Dalgas (2006) study demonstrate that teaching children about self-esteem can improve the way they view themselves which in turn may help them to make better choices, achieve more and support athletes to maintain their own level and to motivate them to cultivate their desire to improve performance.

High self-esteem which reflects positive thoughts and beliefs can be an important contributor to academic success, productive behavior, and mental and physical health in youth (Leary et al., 1995). Guinn et al. (1997) found a significant positive relationship between self-esteem and exercise involvement in female adolescents, Removing negative thoughts and beliefs often makes it possible to break the link that leads to negative feelings and behaviors. CoX (2002) noted that mental skills reflect areas related to personal development and subjective well being as well as performance enhancement. A research by Seligman and Csikszentmihalyi (2000) has demonstrated positive relationships between superior sport performance and self-esteem as a measure of psychological development. In the last two decades, a Varity of intervention techniques have been promoted to help athletes develop mental skills to enhance their performance (Weinberg \& Williams, 2001). Employing a combination of intervention techniques has been shown to be particularly effective in tennis performance (Daw \& 
Burton, 1994), cricket performance (Thelwell et al., 2002), gymnastics performance (kazemi et al., 2003), volleyball performance (Ay et al., 2013) and swimming performance (Ayetal., 2013). While the duration of interventions in the literature ranges from several minutes (Theodorakis, 1996) to one year (Fournier et al., 2005).

Based on this supporting evidence, this study investigates the relation between self-esteem development and learning breaststroke swimming skills performance, (psychological training as applied to swimming skills performance learning), during four weeks of self-esteem development dialogues program engaged to breaststroke swimming skills performance teaching program, for female students in physical education faculty at the university of Jordan who were assigned in swimming course (2) in the first semester 2014/2105 to help students establish a positive perception of themselves and improve personal self-esteem.

The researcher is the teacher of the swimming course in physical education faculty at the University of Jordan , while swimming course is one of the major practice subjects which are part of the syllabus of physical education faculty at the University of Jordan, and all students have to pass it's practical skills performance exams successfully. Swimming course is divided into two parts, namely: swimming (1) which is basic swimming that consists of the teaching crawl and backstroke swimming skills, and swimming (2) which consists of breaststroke swimming and life-saving skills. In swimming course (2) students are educated to learn breaststroke swimming skills performance. Education is an activity, in which there is a process of studying and learning, while learning is not simply gathering knowledge. Learning is a mental process within individuals, it's a process that occurs within individuals that we cannot observe, we can only observe the behavioral changes that are obviously seen (Sanjaya, 2008). The researcher noticed that most of the female students don't show pride in their bodies, they have a lack of confidence to approach swimming activities, expressing fear of water by immature behaviors, and give up easily when not being able to perform.

The researcher is interested in the practice of self-esteem as a psychological skill and its inclusion over the results of learning breaststroke swimming skills performance, however, textbooks lack comprehensive teaching activities related to establishing self-esteem, therefore, it is difficult to enable students to experience self-affirmation and fulfillment and also build self-esteem. How to incorporate self-esteem training into this course is a matter of great urgency. In this light, this study therefore incorporated selfesteem activities into physical education courses to help students establish a positive perception of themselves and develop higher personal self-esteem, it is expected that once a negative thought has been displaced, the students may 
then develop motivations, demonstrated by breaststroke skills performance operating at the highest level (Nideffer et al., 2001). Fitzpatrick et al., (1998) noted that sport appears to be most effective when combined with psychological skills programs, which seeks to address higher personal and psychological development.

\section{Method}

This study investigates the relation between self-esteem development, and learning the breaststroke swimming skills performance (psychological training as applied to swimming performance learning). The subjects were (24) female students at physical education faculty in the university of Jordan, with a mean age of ( $19 \pm 0.5)$ years, who were assigned in swimming course (2) in the first semester of 2014/2015. They were divided randomly into two groups, the experimental group $(n=12)$ and the control group $(n=12)$, both groups completed the self-esteem Questionnaire (Robson Self-Esteem Questionnaire, 1989) pretest which measures the level of their global selfesteem before learning the breaststroke swimming skills performance. The purpose of carrying out the self-esteem questionnaire as a pre-test was to check that there were no differences in individual self-esteem level among all subjects; t-Test was also made for checking the equivalence between the control and experimental groups in age, height and weight. Both groups also went through a physical subjective performance evaluations (selfestimations) pr - test which measures the level of their breaststroke swimming skills performance in a 25 meters indoor swimming pool (water temperature $27 \mathrm{C}$ ). The experimental group executed both physical practice of the skills performance and self-esteem development dialogues program. The control group used physical practice and repeated execution of the skills performance. The program conceited of twelve sessions for 4-weeks, 60 mints a session for both groups. At the end of the program, all subjects finished a post self-esteem Questionnaire which measured the changes in their global self-esteem level after learning the breaststroke swimming skills performance, they also went through a post physical subjective performance evaluation (self-estimations) test which measured their level of the breaststroke swimming skills performance. Conditions did not change between pre- and post-tests in the performance evaluation.

\section{Experimental group}

Subjects received both physical practice of the breaststroke swimming skills performance and self-esteem development dialogues program. This included educational session: physical practice, watching video recording of the skills (modeling) being performed by an elite swimmer on weekly basis, feedback about performance kept given. Where 
the environment remained stable and psychological sessions: positive selfesteem dialogues and instructions, reading a persuasive self-esteem belief paper, as well as a self-esteem workbook which included several exercises and tasks daily practice at home. Subjects were also asked to keep a thought diary over the period of the study to write down details of situations, how they felt and what they think their underlying believes were. The basic techniques were put for creating a positive/ high self-esteem of what the subjects feel their weaknesses, failings or negative core beliefs and where they came from. The subjects will use this technique to challenge and change these weaknesses or failings or negative beliefs, they should try to break their cycle of negative beliefs, think more positively about themselves. Subjects will benefit from this program with the teacher implementing the program. And use these changes to 'intend' an outcome while learning the breaststroke swimming skills performance.

\section{Control group}

Subjects received normal physical practice of the breast stroke swimming skills performance where the environment remained stable. This included learning the performance through physical practice and repeated execution of the performance, watching a video recording of the performance being performed (modeling) by an elite swimmer on weekly basis, feedback about performance kept given beside reading a persuasive paper on the benefits of repeating the tasks.

Robson Self-Esteem Questionnaire RSEQ : The Robson self-esteem questionnaire is a 31-item self-esteem report inventory designed to measure global self-esteem by measuring both positive and negative core feelings about the self, all items are answered using a 7 Likert scale ranging from strongly disagree to strongly agree (where $1=$ Strongly disagree, $2=$ disagree, $3=$ slightly disagree, $4=$ undecided, $5=$ slightly agree, $6=$ agree and $7=$ strongly agree), which indicates the level of global self-esteem.

\section{Procedure}

This study investigates the relationship between self-esteem level and learning the breaststroke swimming performance. The subjects were the female students in level (2) swimming class. They already learn how to swim the free style and backstroke swimming, all the subjects volunteered to participate in the study. Permission to conduct this study was received from the head dean of faculty physical education at the University of Jordan. The students were told the purpose of the study, their rights as participants and asked to sign a consent form. The instruments for measuring the different variables were administered in the pool to the chosen subjects. Participants were novices in breaststroke swimming performance. Two measurements 
were taken; both groups were measured at the beginning (pre-test) in order to establish that all students started at the same level of performance and global self-esteem level. After the completion of the intervention the final measurements were taken (post-test), all subjects went through a (post-test). They completed the post-test self-esteem Questionnaire which measured the changes in their global self-esteem level, and the physical subjective performance evaluation (self-estimations) post-test which measured their level of the breast stroke swimming performance to note the impact of the intervention on the student's performance in breast stroke swimming.

\section{The program}

In the first training unit, after warming up in the water, all subjects performed the breaststroke swimming skills and the test of the performance was conducted. The instruction that was given to subjects before they started was: "do the best you can" subjects were informed about their scores in the test, and they filled out the self-esteem questionnaire. The program conceited of twelve sessions for 4-weeks, 3 sessions a week, 60 minutes a session for both groups.

\section{The experimental group sessions}

- 15 minutes: self-esteem development dialogues program which included the subjects of (identify your negative core beliefs, how to value yourself and others, how to avoid friends and people who encourage the negative beliefs and opinions that you hold, how to Set yourself a challenge, how to be assertive, how to build your confidence and to show pride in your work, how to trust your ideas and to engage in work with confidence, how to set goals independently, how to adapt to changes, how to create a cheerful mood, how to describe yourself in positive terms, physical regular activity is good for mental health, mindfulness, how to set your diet, How to get enough sleep, how to pay attention to the present moment, daily positive thinking exercises).

- $\quad 10$ minutes: warm up in the pool.

- $\quad 30$ minutes: learning breaststroke performance.

- 5 minutes: cool down.

\section{The control group sessions}

- $\quad 10$ minutes: warm up in the pool.

- $\quad 45$ minutes: learning breaststroke performance.

- $\quad 5$ minutes: cool down. 


\section{Teaching breaststroke skills performance program}

Breaststroke is one of the four competitive strokes. It is also a valuable survival stroke. When swimming the breaststroke the swimmer is prone in the water, and the arm and leg actions are symmetric. The swimmer breathes in at the beginning of each arm stroke. Breaststroke is the only competitive stroke where the arm recovery is carried out under water and where a greater amount of frontal resistance is experienced. The arm action is an out sweep, down sweep, in sweep and up sweep with recovery in a streamline position. The leg kick in breaststroke is probably the most difficult of all kicks for swimmers to master and may take some time. The leg action is simultaneous and is sometimes described as a "whip kick." In addition to the breathing, the correct timing of the arms and legs is very important (Hollander et al., 2009 \& Shengen, 2008).

The teaching steps for breaststroke swimming were:

- Teaching the breaststroke legs kick : Standing individual leg kick, breaststroke kick on a chair, breaststroke kick on the floor, breaststroke kick on pool edge, breaststroke kick while in the water holding the side of the pool, kick for 15 meters holding a kickboard, kick for 15 meters without a kickboard.

- Teaching the breaststroke arms stroke: breaststroke arm stroke on dry land, breaststroke pull in chest-deep water without the kick press the body forward with the hands.

-Teaching breaststroke breathing - timing: practice breaststroke with regular breathing for 15 meters.

- Teaching timing of leg kick, arm action and breathing: the timing rhythm is - pull - kick - hands forward glide, start a new breaststroke cycle once the momentum of the glide fades, emphasizing the glide and reducing the number of strokes that it takes to swim a width (Schmidt \& Wrisberg, 2004 ; Klika \& Thorland , 1994). The researcher in this study is expert swimming instructors for fifteen years, she evaluated the subjects `skills performance in breaststroke swimming in pre and post-tests.

\section{Results and discussion}

Table (1) t-Test for checking the equivalence between the control and experimental groups in age, height, weight, self-esteem level and breaststroke swimming. 
Table (1) means Physical characteristics for the subjects.

\begin{tabular}{|c|c|c|c|c|c|c|}
\hline Variables & Group & Mean & $\mathrm{Sd}$ & Calculate t & Critical t & Prob \\
\hline \multirow{2}{*}{ age(years) } & Control & 19.853 & 0.498 & \multirow{2}{*}{1.008} & \multirow{10}{*}{2.07} & \multirow{2}{*}{ N.S } \\
\hline & Experimental & 19.500 & 0.500 & & & \\
\hline \multirow{2}{*}{ weight(kg) } & Control & 68.367 & 2.853 & \multirow{2}{*}{1.021} & & \multirow{2}{*}{ N.S } \\
\hline & Experimental & 67.833 & 2.824 & & & \\
\hline \multirow{2}{*}{ height(cm) } & Control & 178.750 & 3.325 & \multirow{2}{*}{1.032} & & \multirow{2}{*}{ N.S } \\
\hline & Experimental & 178.500 & 3.378 & & & \\
\hline \multirow{2}{*}{ breaststroke } & Control & 13.08 & 2.46 & \multirow{2}{*}{1.92} & & \multirow{2}{*}{ N.S } \\
\hline & Experimental & 16.05 & 2.62 & & & \\
\hline \multirow{2}{*}{$\begin{array}{l}\text { self-esteem } \\
\text { level }\end{array}$} & Control & 32.750 & 3.320 & \multirow{2}{*}{1.595} & & \multirow{2}{*}{ N.S } \\
\hline & Experimental & 33.417 & 2.629 & & & \\
\hline
\end{tabular}

Table (1) indicates that the calculated t values were not significant when compared to critical t value 2.07 for all the included variables. The probability values supports that there were no significant differences between the two groups at 0.05 level concluding the two groups are equivalent.

Table (2) means, sd and t-test between the pre and post test for self- esteem level in each group.

\begin{tabular}{|c|c|c|c|c|c|c|c|}
\hline \multirow{2}{*}{ Variable } & \multirow{2}{*}{ Group } & \multicolumn{2}{|c|}{ Pre } & \multicolumn{2}{|c|}{ Post } & \multicolumn{2}{c|}{ T } \\
\cline { 3 - 8 } & & $\mathrm{M}$ & $\mathrm{sd}$ & $\mathrm{M}$ & $\mathrm{Sd}$ & Calculated & Sig \\
\hline $\begin{array}{c}\text { Self- } \\
\text { esteem } \\
\text { level }\end{array}$ & experimental & 33.417 & 2.629 & 48.167 & 3.508 & 14.736 & $\mathrm{~S}$ \\
\cline { 2 - 8 } & Control & 32.750 & 3.320 & 34.333 & 2.528 & 5.744 & $\mathrm{~S}$ \\
\hline
\end{tabular}

Table (2) shows the values of means, standard deviations and calculated t between the pre and post tests in each group for self-esteem level. the experimental pre test mean 33.417 with standard deviation 2.629 while the post test mean was 48.167 with standard deviation of 3.508 ; the calculated t value 14.736 was greater than the critical value 2.20 with 11 D.F at 0.05 level of significance indicating that mean differences were significant in favor of the post test. While the control pre test mean 32.750 with standard deviation 3.320 while the post test mean was 34.333 with standard deviation of 2.258; the calculated t value 5.744 was greater than the critical value 2.20 with 11 D.F at 0.05 level of significance indicating that mean differences were significant in favor of the post test. Significant differences were found between the pre- and post-test scores in the (self-esteem questionnaire) for both experimental and control group. Both groups showed improvement.

The mean (self-esteem questionnaire) post-test scores provided evidence that both groups had higher level of self-esteem than the pre-test. This result shows that participating in the swimming course for four weeks had an effect on the students self-seem level positively, this correlates with 
some studies, in their study King et al (1989) found that the psychological effects often associated with participation in sport, improved self-esteem, self-efficacy and perceived competence, have also been identified as resulting from long-term participation in an exercise program. Whereas, Long and Sanderson (1998) found that, among the supposed beneficial outcomes associated with sports participation, the individual psychological effects, improved self-esteem and self-confidence - were easily the most important perceived benefits. Clearly, benefits accruing to individual participants are regarded as the most likely and most tangible benefits of sports participation. The positive mental changes that occur as a consequence of participation in physical activity may be caused by a number of factors accumulations of short-term improvements to mood (Steptoe, 1992). The mean in the (self-esteem questionnaire) post-test scores also provided evidence that the experimental group has higher level of self-esteem than the control group. The experimental group scores provide evidence that using self-esteem development dialogues program, is a useful tool to improve the highest level of self-esteem. This is consistent with the findings of Dalgas (2006) and Whitesell et al., (2009) that self-esteem is human kind's most basic psychological need and the corner stone of contemporary youth's development of their overall faculties. An ability to maintain a high degree of self-esteem can positively affect the life and academic achievements of children and teenagers. Boden et al (2008) found that Students with positive self-esteem typically demonstrate a high degree of autonomy and selfconfidence, self-respect, and satisfaction with themselves. In their study Ekeland et al., (2004), noted that in the course of growing up, children and teenagers often face psychological problems. However, it has been shown that such problems may be prevented by improving self-esteem.

Table (3) means, sd and t-Test between the pre and post test for Breaststroke performance evaluation in each group.

\begin{tabular}{|c|c|c|c|c|c|c|c|}
\hline \multirow{2}{*}{ Variable } & \multirow{2}{*}{ Group } & \multicolumn{2}{|c|}{ Pre } & \multicolumn{2}{c|}{ Post } & \multicolumn{2}{c|}{$\mathrm{T}$} \\
\cline { 3 - 8 } & & $\mathrm{M}$ & $\mathrm{Sd}$ & $\mathrm{M}$ & $\mathrm{Sd}$ & Calculated & Sig \\
\hline \multirow{2}{*}{$\begin{array}{c}\text { Breaststroke } \\
\text { performance }\end{array}$} & experimental & 16.05 & 2.62 & 17.10 & 2.37 & 3.28 & $\mathrm{~S}$ \\
\cline { 2 - 8 } & control & 13.08 & 2.46 & 14.03 & 2.65 & 2.96 & $\mathrm{~S}$ \\
\hline
\end{tabular}

Table (3) indicates the values of means, standard deviations and calculated $\mathrm{t}$ between the pre and post tests in each group for the breaststroke performance evaluation. The experimental pre-test mean 16.05 with standard deviation 2.62 while the post-test mean was 17.10 with standard deviation of 2.37; the calculated t value 3.28 was greater than the critical value 2.20 with 11 D.F at 0.05 level of significance indicating that mean differences were significant in favor of the post test. While the control pre-test mean was 13.08 with standard deviation 2.46 while the post-test mean was 14.03 with 
standard deviation of 2.65 ; the calculated t value 2.96 was greater than the critical value 2.20 with 11 D.F at 0.05 level of significance indicating that mean differences were significant in favor of the post test for both experimental and control group.

A significant difference was found between the pre and post-test scores awarded by the teacher for both experimental and control group in the breaststroke swimming skills performance. The control group subjects improved their performance between the pre- and post-test in breaststroke swimming skills performance. The increased scores caused by the duration of the training session, the repeated execution of the skills (physical practice) and the feedback information after modeling the motor skills. There are different forms of training by means of which learning of motor skills can be improved. Modeling or direct demonstration. Modeling is one of the most usual forms of giving instruction during the learning of new motor tasks, it has been defined as a cognitive process in which the learner attempts to imitate an observed skill performed by another individual (McCullagh \& Weiss, 2001), Morris et al (2005) noted that Humans are capable of imitating the motor actions of others, because the mind "photographs" the motor skill and uses it as foundation of the performance. The control group subjects, also, watched a video recording of an elite performed the breaststroke swimming skills performance correctly (Symbolic modeling) as the teacher verbally highlighted relevant components of the skills In the pool, and provided verbal positive feedback for the correct performance components and corrective feedback for incorrect performance components, video modeling established as effective procedures for enhancing performance watching a video of an expert modeling (performing) improved breaststroke swimming skills performance. By means of modeling, the novice quickly forms himself an idea of the movement to be executed (SooHoo, at el., 2004). Modeling is effective when processes like attention is present, attention requires the learner to attend to salient cues of the observed performance provided by the model. Then, the learner retains these important cues in memory for later attempts of the desired skill without additional modeling. Numerous researchers have found modeling to be effective in facilitating learning a new motor skill and improving performance (McCullagh \& Weiss, 2001). Taken together, the above reviewed evidence, and control group scores in this study indicate that usual forms of giving instruction during the learning of new motor skills are possible tools for learning, physical practice via modeling have been proven to be a an effective tool for learning new motor skills (SooHoo, at el., 2004).

The increased score in the experimental group suggests that the combination of psychological program (self-esteem improvement) and physical practice enhanced learning the breaststroke swimming and 
improved performance. The efficacy of psychological program has been documented by a large body of scientific evidence; Complementary to this evidence, Brouziyne (2005) noted that psychological training can be used effectively to improve performance with beginners. In recent years, psychological programs improvement had emerged as a promising technique to improve motor skills Performance, it has been well documented that populations such as athletes and dancers benefit from engaging in psychological training (Braun et al, 2006). These results are in agreement with previous research which suggests that mental training improves the learning of a motor task in adult subjects (Gentili, at el., 2010), beside the role that the instructor played in teaching the experimental group subjects and guiding them how to use the psychological skill of self-esteem during learning the breaststroke swimming skills in order to obtain the desire performance. Good teaching guides students' efforts, enabling them to learn more efficiently, this is consistent with Jekauc and woll (2006) that coaches play an important role in teaching athletes the various uses of psychological skills and may aid in determining the function of skills athletes need to use in order to obtain desired outcomes.

Table (4) t-Test results between the control and experimental groups in breaststroke performance and self-esteem level in the post test.

\begin{tabular}{|c|c|c|c|c|c|c|}
\hline \multirow{2}{*}{ Variables } & \multirow{2}{*}{ Group } & \multicolumn{2}{|c|}{ Post } & \multirow{2}{*}{$\begin{array}{c}\text { Calculate } \\
\mathrm{t}\end{array}$} & \multirow{2}{*}{$\begin{array}{c}\text { Critical } \\
\mathrm{T}\end{array}$} & \multirow{2}{*}{ Probe } \\
\hline & & $M$ & $\mathrm{Sd}$ & & & \\
\hline \multirow{2}{*}{$\begin{array}{l}\text { Self-esteem } \\
\text { level }\end{array}$} & experimental & 48.167 & 3.508 & \multirow{2}{*}{11.076} & \multirow{2}{*}{2.07} & S \\
\hline & Control & 34.333 & 2.528 & & & \\
\hline \multirow{2}{*}{$\begin{array}{l}\text { Breaststroke } \\
\text { performance }\end{array}$} & experimental & 17.10 & 2.37 & \multirow{2}{*}{4.14} & \multirow{2}{*}{2.07} & \multirow{2}{*}{ S } \\
\hline & Control & 14.03 & 2.65 & & & \\
\hline
\end{tabular}

Table (4) indicates that the calculated t value was greater than the critical t value 2.07 with $11 \mathrm{D}$.F at 0.05 level for the breaststroke performance and self-esteem level suggesting significant mean differences between the two groups in favor of the experimental group. The mean self-esteem level scores and the breaststroke performance scores in the post-test showed that experimental group has higher self-esteem level and higher breaststroke performance than the control group.

The mean (self-esteem questionnaire) scores and the breaststroke swimming skills performance level scores in the post-test showed that experimental group has higher self-esteem and higher skills performance level than the control group. Researcher in this study concluded that 
participants with reportedly high self-esteem improved performance on the task more than those identified with lower self-esteem. Self-esteem is human kind's most basic psychological need and the corner stone of contemporary youth's development of their overall faculties (Dalgas, 2006 \& Whitesell et al., 2009).

The control group improved their self-esteem level, and enhanced their skills performance in the post-test as well, via physical practice alone. Furthermore, the experimental group improved more on average from the first (pre-test) to the second measurement (post-test) when compared to the control condition, which proves that self-esteem improvement before the actual execution of the skills has a positive effect on learning the new skills in swimming (Jekauc \& Woll, 2006).

This is consistent with the findings of Sadeghi et al (2010) when providing an accurate and efficient mental representation before a task is formed, a task can be learned more quickly and then analyzed and improved. Weinberg and Williams (2002) noted that psychological skills practice improve the learning and performance of variety of motor skills.

Psychological skills program such as self-esteem improvement program engaging with motor movement plays an important role in learning of complex motor skills, and has practical implications for skills learning. Self-esteem improvement can facilitate the learning and performance of motor skills. It is an intervention, which may bring about favorable outcomes including better self-confidence and improved performance (Moran, 2012).

The increased scores in this study suggest that the combination of self-esteem improvement program and physical practice thought to be more efficient to enhance learning new swimming skills and to improve performance more than physical practice alone (Moran, 2012; Dalgas, 2006; Whitesell et al., 2009).

When established higher self-esteem, students in the experimental group showed more pride in their bodies, started to have positive perception of themselves and had higher confidence to approach swimming activities which developed motivations to go on actively in the motor learning process, they had more determination and more productive behaviors which made them learn the breaststroke swimming skills performance better than the control group. Boden et al (2008) noted that having high level of self-esteem creates more motivations to learn motor skills. Research in Sport Psychology considers motivation as a behavior directed toward a goal or the internal and emotional awakening interest in something, being willing to reach it (Machado,2006), and its importance is associated with adherence to physical practice, income, physical conditioning, fun, learning and living with friends, and success experience in sport activities (Moreno et al., 2006). 
Once you improved the student self-esteem you can create more effective learning experiences, enhance student enjoyment which made him/her more motivated to progress and improve learning motor skills, enhance student comfort and thereby help learning internal feedback and developing kinesthetic awareness creating a positive learning environment and improve the desire learning outcome (Coppersmith, 1981). This is consistent with the findings of Dalgas (2006) and Whitesell et al (2009) who found that an ability to maintain a high degree of self-esteem can positively affect the life and academic achievements of children and teenagers. But having high self-esteem does not mean you will always feel confident about work and skills nor have successful relationships. However, positive selfesteem is a strong predictor of happiness. If your core belief about yourself is mainly positive you may still associate with some of these behaviors, but your ability to cope with them will be much better. While part from its physical and mental effects, low self-esteem has been linked to poor academic achievement, depression, smoking, crime, and other deleterious risky social behaviors (Donnelly et al., 2008). In conclusion, learning motor skills and sport appear to be most effective when combined with programs to improve self-esteem (Fitzpatrick et al., 1998). Dalgas (2006) study demonstrate that teaching children about self-esteem can improve the way they view themselves which in turn may help them to make better choices, achieve more, and be better equipped to face life's challenges. Schools and educators are in a unique position to be able to teach students Strategies to raise self-esteem provide guidance and follow up activities, and monitor the impact of self-esteem enhancement education over time.

In conclusion, the present study gives support for the notion that participation in a worthwhile dialogues program to improve self-esteem was an important aspect for learning the skills of breaststroke swimming performance, which influenced the academic development of the female students who were the subjects in this study. This research suggests that offering self-esteem dialogues development programs during teaching sport skills help learners to develop and/ or retain a positive, develop motivations to perform the task and get healthy self-image. The benefits appear to be particularly encouraging among females and students of low socioeconomic status. A group-based intervention with standardized lessons can easily be incorporated into established curricula or adapted to fit the needs of a particular school, youth organization, or community program. For the purposes of this study, the intervention was delivered by swimming instructor for physical education faculty female students at the university of Jordan, however the self-esteem improvement dialogues program could also be taught by coaches, school teachers, counselors, youth leaders or parents in a variety of settings in which students feel comfortable reflecting on their 
feelings and attitudes about themselves, This study may provide teachers and school administrators with information on how to design self-esteem elements into the regular curriculum to improve students' self-esteem without additional class hours. Overall, findings reinforce the importance of selfesteem. In physical education, Students will learn best when physically and mentally ready.

\section{Conclusion}

The results of this study showed that learning new swimming skills performance engaged to dialogues for self-esteem development enhanced learning and improved performance of the breaststroke swimming skills.

\section{References:}

Addeo, R \& Greene, A (1994). Construct validity of the Robson self-esteem questionnaire in a college sample. Educational \& Psychological Measurement, 54 (2).

Ay, K., Halaweh, R \& Abu-Taeb, M (2013).The effect of movement imagery training on learning forearm pass in volleyball. Education, International academic Journal. Vol.134, No. 2 . Mobile, Alabama

Ay, K., Halaweh, R \& Abu-Taeb, M (2013).Positive self-talk and its effect on learning the grab start skill in swimming and self-efficacy improvement, Journal of physical education and sport (JPES), 13(4), Art 90, pp. 578 - 582. Bandura, A (1977). Self-efficacy: Toward a unifying theory of behavioral change. Psychol. Rev. 84:191-215.

Bandura, A (1978). Social Foundation of Thought and Action: A Social Cognitive Theory. Englewood Cliffs, N.J.: PrenticeHall.

Boden, J. M., Fergusson, D. M., \& Horwood, L. J. (2008). Does adolescent self-esteem predict later life outcomes? A test of the causal role of selfesteem. Development and Psychopathology, 20(1), 319-339.

Braun S, Beurskens A, Borm P, Schack T, Wade D,(2006). The effects of mental practice in stroke rehabilitation: a systematic review. Arch Phys Med Rehabil; 87:842-52.

Brouziyne, C, (2005),Perceptual and Motor Skills:, Volume 101, 203-211.

Canossa S, Fernandes R, Carmo C, Andrade A, Soares S(2007). Ensino multidisciplinary em natação: reflxão metodológica e proposta de lista de verifiação.Motricidade; 3(4):82-99.

Coppersmith, S (1981). Self-esteem inventories (SEI). Palo Alto, CA: Consulting Psychologists Press.- Cohn, P. (2006) Self-esteem in the athlete. Brian Mackenzie's Successful Coaching, (ISSN 1745-7513/ 38/ December), p. 9-10.

Cox, R (2002). Sport psychology: Concepts and applicatios ( $5^{\text {th }}$ Ed.). New York: McGraw-Hill. 
Dalgas, P. (2006). Effects of a self-esteem intervention program on schoolage children. Pediatric Nursing, 8, 341-349.

Daw, J \& Burton, D (1994). Evaluation of a comprehensive psychological skills training program collegiate tennis players, the sportpsychologist, 8, 3757.

Donnelly, J., Young, M., Pearson, R., Penhollow, T \& Hernandez, A (2008). Area specific self-esteem, values, and adolescent substance use. Journal of Drug Education, 3S(4), 389-403.

Ekeland, E., Heian, F., Hagen, K., Abbott, J., \& Nordheim, L (2004). Exercise to improve self-esteem in children and young people. Cochrane Database of Systematic Reviews, 7, CD003.

Epuran, M.; Holdevici I.; Tonipa F., (2001), Performance Sport Psychology: Theory and Practice. Fest Publishing House, Bucharest.

Fitzpatrick, S., Hastings, A. and Kintrea, K (1998) Including Young People in Urban Regeneration: A Lot to Learn? Bristol, The Policy Press.

Fournier, J., Calmels, C., Durand-Bush, N \& Salmela, J (2005). Effect of a season- long PST program on gymnastic performance and on psychological skill development, International journal of sport and exercise psychology, 3, 59-77.

Gentili, R., Han, C., Schweighofer, N., \& Papaxanthis, C. (2010). Motor learning without doing: Trial-by-trial improvement in motor performance during mental training. Journal of Neurophysiology, 104(2), 774-778.

Guinn, B., T. Semper and L. Jorgensen (1997). Mexican American female adolescent self-esteem: The effect of body image, exercise behaviour and body fatness. Hispanic. Journal of behavioural Science. 19(4): 517-526.

Hanton, S \& Jones, G (1999). The acquisition and development of cognitive skills and strategies: I. Making the Butterflies fly in formation, the sport psychologist, 13, 1-21.

Harter, S (1978). Effectance motivation reconsidered: Toward a developmental model. Hum. Dev. 21:34-64.

Hollander, P., Huijng , a.\& de Groot, G(2009). Biomechanics and medicine in swimming Champaign, IL: Human kinetics PP, 204-217.

Jekauc, D., \& Woll, A. (2006). Effektivität einer ergebnisfokussierten Mentaltechnik. In M. Raab, A. Arnold, K. Gärtner, J. Köppen, C. Lempertz, N.

Kahne, J (1996). The Politics of Self-esteem. American Educational Research Journal, 33 (1), 3-22.

Kazemi, R., Khaberi, M \& Farokhi, A (2003). The effect of mental training on the performance of elite gymnasts. In Y.L. Hanin (chair), Oral presentations, Symposium conducted at the meeting of the $2^{\text {nd }}$ international congress on psychology applied to sport, Madrid, Spain. 
King, A.C. et al (1989) The Influence of Regular Aerobic Exercise on Psychological Health, Health Psychology, 8, pp.305-24

Klika, R \& Thorland, W (1994). Physiological determinants of sprint swimming performance in children and young adults, Pediatric exercise science, 6 .59-68.

Leary, M., Schreindorfer, L \& Haupt, A (1995). The role of self-esteem in emotional and behavioral problems: Why is low self-esteem dysfunctional? Journal of Social and Clinical Psychology, 14(32), 297-314.

Lishner, K \& Myers, J (1997). Building Self-esteem through the Camp Experience. Camping magazine. 70 (1).

Long, J. and Sanderson, I. (1998) Social Benefits of Sport : Where's the Proof?, Sport In The City: Conference Proceedings Volume 2, Sheffield, 2-4 July 1998, pp.295-324, Loughborough University / Sheffield Hallam University / The University of Sheffield

Machado AA, (2006).Brandão MRF. Performance esportiva de adolescentes: inflências psicológicas externas. Motriz;12(3):262-8.

Magill, R (2007). Motor learning and control: concepts and applications. 8ed. New York: McGraw-Hill.

McCullagh, P., \& Weiss, M. R. (2001). Modeling: Considerations for motor skill performance and psychological responses. In R. Singer, H. Hausenblas, \& C. Janelle (Eds.), Handbook of sport psychology (pp. 205-238). New York: Wiley \& Sons.

Moran, A (2012).Sport and exercise psychology :A critical introduction(2nd edn).London, Routledge, P414-415.

Moreno RM, Dezan F, Duarte LR, Schwartz GM (2006). Persuasão e motivação: interveniências na Atividade Física e no Esporte. Revista DigitalEFDesportes; 11(103):1-1.

Morris, T., Spittle, M., Watt, A.P. (Eds.).(2005). Technical Aids to Imagery. In Imagery in Sport (pp. 237-266). Champaign, IL: Human Kinetics.

Nideffer, R., Sagal, M., Lowry, M \& Bond, J (2001). Identifying and developing world-class performance. In G. Tenenbaum (ED.). The practice of sport psychology (pp.129-144). Morgan town, WV: Fitness Information Technology.

Pellegrini, A (2000). A aprendizagem de habilidades motoras I: o que muda com a prática. Rev Paul Educ Fís;(3):29-34.

Robson, P. J. (1989). Development of a New Self Report Questionnaire to

Measure Self Esteem. Psychological Medicine, 19, 513-518.

Sadeghi, H., Omar-Fauzee, M.S., Jamalis, M., Ab-Latif, R., \& Cheric, M.C. (2010). The mental skills training of University soccer players. International Education Studies, 3(2), 81-90.

Sanjaya, W. (2008). Strategi Pembelajaran (Berorientasi Standar Proses Pendidikan). Jakarta: Prenada Media. 
Santos AC, Gonçalves J, Pereira RG(2008). Estudo comparativo da organização das escolas de natação: três casos versus três parâmetros do processo ensino-aprendizagem. Motricidade; 4(3):87-93.

Schmidt, R \& Wrisberg, C (2004). Motor learning and performance (3er Ed.). Champaign, IL: Human Kinetics.

Seligman, M \& Csikszentmihalyi, M (2000). Positive psychology: An introduction, American sychologist, 55.5-14.

Shengen, A (2008). Relationship of certain physical measurement to swimming speed. R. Co. UOL. 47. No A, P. 810.

SooHoo, S., Takemoto, K., \& MaCulagh, P. (2004). A comparison of modelling and imagery on the performance of motor skill. Journal of Motor Behavior, 27(4), 349-367.

Steptoe, A. (1992) Physical Activity and Well-Being, In: Norgan, N.G. Physical Activity and Health, Cambridge, University Press.

Thelwell, R., Maynard, I \& Graydon, J (2002). The effects of a mental skills package on repeatable good performance in cricketers: A group analysis. Journal of sport science, 20, 72.

Theodorakis, Y (1996). The influence of goals, commitment, self-efficacy and self satisfaction on motor performance, Journal of applied sport psychology, 8, 171-182.

Ting, L (2015), Applying virtual reality teaching. Environmental science and information application technology-chan (ED.). Taylor AND France group, London, ISBN: 978-1-138-02814-2.

Tremayne, P \& Tremayne, B (2004). Children and sport psychology. In T.Morris \& J.Sum-mers(Eds.), Sport psychology : Theory, application and issues ( $2^{\text {nd }} .$, pp.529-546).Milton, Queensland, Australia, Wiley.

Weinberg, R \& Williams, J (2002). Integrating and implementing a psychological skills training program. In J.M. Williams (Ed.), Applied sport psychology: Personal growth to peak performance (4 ${ }^{\text {th }}$ Ed., pp.347-377). Mountain View, CA: May field.

Whitesell, N. R., Mitchell, C. M., \& Spicer, P. (2009). A longitudinal study of self-esteem, cultural identity, and academic success among American Indian adolescents. Cultural Diversity \& Ethnic Minority Psychology, 75(1), 38-50.

Zevin, D \& McPherson, C (1989). Into adolescence: Enhancing self-esteem. Santa Cruz, CA: Network Publications.

Robson Self-Esteem Questionnaire-RSEQ 


\begin{tabular}{|c|c|c|c|c|c|c|c|c|}
\hline $\begin{array}{l}\mathrm{N} \\
\mathrm{o}\end{array}$ & Items & $\begin{array}{c}\text { Stro } \\
\text { ngly } \\
\text { Dis } \\
\text { agre } \\
\text { e }\end{array}$ & $\begin{array}{l}\text { Dis } \\
\text { agre } \\
\text { e }\end{array}$ & $\begin{array}{l}\text { Slightly } \\
\text { disagree }\end{array}$ & $\begin{array}{l}\text { Unde } \\
\text { cided }\end{array}$ & $\begin{array}{l}\text { Sli } \\
\text { ghtl } \\
\text { y } \\
\text { agr } \\
\text { ee }\end{array}$ & $\begin{array}{l}\mathrm{Ag} \\
\text { ree }\end{array}$ & $\begin{array}{l}\text { Stro } \\
\text { ngl } \\
\text { y } \\
\text { agre } \\
\text { e }\end{array}$ \\
\hline 1 & $\begin{array}{l}\text { I am not embarrassed to let people know } \\
\text { my opinions. ** }\end{array}$ & & & & & & & \\
\hline 2 & I seem to be very unlucky. * & & & & & & & \\
\hline 3 & I am easy to like. $* *$ & & & & & & & \\
\hline 4 & $\begin{array}{l}\text { If a task is difficult that just makes me all } \\
\text { the more determined. } * *\end{array}$ & & & & & & & \\
\hline 5 & $\begin{array}{l}\text { If a task is difficult that just makes me all } \\
\text { the more determined. } * *\end{array}$ & & & & & & & \\
\hline 6 & $\begin{array}{l}\text { There are lots of things I'd change about } \\
\text { myself if I could. ** }\end{array}$ & & & & & & & \\
\hline 7 & $\begin{array}{c}\text { I can never seem to achieve anything } \\
\text { worthwhile. * }\end{array}$ & & & & & & & \\
\hline 8 & I do not care what happens to me. * & & & & & & & \\
\hline 9 & I have control over my own life. $* *$ & & & & & & & \\
\hline $\begin{array}{l}1 \\
0\end{array}$ & $\begin{array}{l}\text { Most people find me reasonably attractive. } \\
\qquad * *\end{array}$ & & & & & & & \\
\hline $\begin{array}{l}1 \\
1\end{array}$ & I am glad I am who I am. ** & & & & & & & \\
\hline $\begin{array}{l}1 \\
2\end{array}$ & $\begin{array}{l}\text { Most people would take advantage over } \\
\text { me if they could. ** }\end{array}$ & & & & & & & \\
\hline $\begin{array}{l}1 \\
3\end{array}$ & I am a reliable person. $* *$ & & & & & & & \\
\hline $\begin{array}{l}1 \\
4\end{array}$ & $\begin{array}{l}\text { It would be boring if I talked about myself. } \\
\qquad *\end{array}$ & & & & & & & \\
\hline $\begin{array}{l}1 \\
5\end{array}$ & $\begin{array}{c}\text { When I am successful there is usually a lot } \\
\text { of luck involved. * }\end{array}$ & & & & & & & \\
\hline $\begin{array}{l}1 \\
6\end{array}$ & I have a pleasant personality. $* *$ & & & & & & & \\
\hline $\begin{array}{l}1 \\
7 \\
\end{array}$ & $\begin{array}{l}\text { I never feel down in the dumps for very } \\
\text { long. ** }\end{array}$ & & & & & & & \\
\hline $\begin{array}{l}1 \\
8\end{array}$ & I often feel humiliated. * & & & & & & & \\
\hline $\begin{array}{l}1 \\
9\end{array}$ & $\begin{array}{l}\text { I can usually make my mind up and stick } \\
\text { to it. } * *\end{array}$ & & & & & & & \\
\hline $\begin{array}{l}2 \\
0\end{array}$ & $\begin{array}{c}\text { Everyone else seems much more confident } \\
\text { and contented than me. * }\end{array}$ & & & & & & & \\
\hline $\begin{array}{l}2 \\
1\end{array}$ & $\begin{array}{l}\text { Even when I quite enjoy myself there } \\
\text { doesn't seem much purpose to it all. * }\end{array}$ & & & & & & & \\
\hline $\begin{array}{l}2 \\
2\end{array}$ & $\begin{array}{l}\text { I often worry about what other people are } \\
\text { thinking about me. * }\end{array}$ & & & & & & & \\
\hline $\begin{array}{l}2 \\
3 \\
\end{array}$ & $\begin{array}{c}\text { There is a lot of truth in the saying: "What } \\
\text { will be, will be." ** }\end{array}$ & & & & & & & \\
\hline $\begin{array}{l}2 \\
4 \\
\end{array}$ & I look awful these days. * & & & & & & & \\
\hline $\begin{array}{l}2 \\
5\end{array}$ & $\begin{array}{l}\text { If I really try I can overcome most of my } \\
\text { problems. } * *\end{array}$ & & & & & & & \\
\hline $\begin{array}{l}2 \\
6 \\
\end{array}$ & It's pretty tough to be me. * & & & & & & & \\
\hline
\end{tabular}




\begin{tabular}{|l|c|l|l|l|l|l|l|l|}
\hline 2 & I feel emotionally mature. ** & & & & & & & \\
\hline 7 & When people criticize me I often feel & & & & & & & \\
8 & helpless and second rate. * & & & & & & & \\
\hline 2 & When progress is difficult, I often find & & & & & & & \\
9 & myself thinking it's just not worth the \\
effort. * & & & & & & & \\
\hline 3 & I can like myself even when others don't. \\
0 & & & & & & & \\
\hline 3 & Those who know me well are fond of me. \\
1 & $* *$ & & & & & & & \\
\hline
\end{tabular}

*(Negative response) $-* *$ (Positive response) 